\title{
Sterilisation of incompetent mentally handicapped persons: a model for decision making
}

Joke P M Denekens, Herman Nys and Hugo Stuer University of Antwerp, University of Leuven and University of Antwerp, Belgium respectively

\begin{abstract}
Doctors are regularly confronted with requests for sterilisation of mentally handicapped people who cannot give consent for themselves. They ought to act in a medical vacuum because there doesn't exist a consensus about a model for decision making on this matter.

In this article a model for decision making is proposed, based on a review of the literature and our own research data. We have attempted to select and classify certain factors which could enable us to arrive at an ethically justifiable method of making a medical decision.

In doing so we distinguish two major criteria: heredity and parenting competence, and six minor criteria: conception risk, IQ, age, personality, medical aspects and prognosis and finally support and guidance for the mentally handicapped person. The major criteria give rise to a "situation of necessity". In this situation the physician is confronted with a conflict of values and interests. The minor criteria are of an entirely different ethical order. They can only be considered once the major criteria have created a "situation of necessity".

Ultimately it comes down to deciding whether the benefits of sterilisation outweigh the drawbacks and whether the means are appropriate to the end, where efficient contraception is the end and irreversible sterilisation is the means.
\end{abstract}

(Fournal of Medical Ethics 1999;25:237-241)

Keywords: Sterilisation; mentally handicapped persons; decision making

\section{Introduction}

The theme of sterilisation of the mentally handicapped is currently very much in the news. The world was recently dismayed to learn that thousands of women were sterilised in Sweden between 1935 and 1976 because their behaviour was regarded as "unacceptable".

These sterilisations took place in a social context, where it was assumed on the basis of sci- entific hypothesis that all forms of mental retardation were hereditary. ${ }^{1}$

In the first part of this century eugenic sterilisations took place in many countries, all over the world.

Applebaum wrote about the United States of America:

"Eugenic sterilisation and the laws that allowed its practice are not distant, either in time or geography. By 1935, backed up by Buck v Bell decrying 'three generations of imbeciles' as enough, 30 states had passed sterilisation laws, hoping to improve the population as a whole". ${ }^{2}$

As a result of these laws some 60,000 persons with mental illness and mental retardation were involuntarily sterilised during the first part of this century. ${ }^{3}$ By 1937 225,000 people had been sterilised in Germany. ${ }^{4}$ New understanding has progressively undermined the heredity argument. ${ }^{5}$

Moreover new developments in special education and training such as normalisation ${ }^{6}$ and mainstreaming ${ }^{7}$ have brought about a fundamental change in how mental retardation is viewed. The Declaration on the Rights of Mentally Retarded Persons in 1971 by the United Nations Assembly, proclaims that the mentally retarded person has, to the maximum degree of feasibility, the same rights as other human beings. ${ }^{8}$

Most mentally handicapped persons now live in a mixed environment. Consequently the question of fertility control is increasingly relevant. Moreover a suitable form of conception control for mentally handicapped people is not always easy to find. ${ }^{9}$ Doctors are regularly confronted with requests for the sterilisation of mentally handicapped people. In the medical world there is no consensus about a model for decision making in this area.

By drawing on the data available in the literature, and drawing on our own research data, ${ }^{10}$ we have attempted to select and classify certain factors which could enable us to arrive at 
an ethically justifiable method of medical decision making when confronted with a request for the sterilisation of an incompetent mentally retarded person.

\section{Major criteria for the evaluation of a request for sterilisation}

The points of departure for the evaluation of a request to sterilise a mentally handicapped person, unable to decide for herself or himself, are the ideas of "respect" for and the "best interest" of the mentally handicapped subject. The implication here is that the mentally handicapped person must, as far as possible, be involved in the decision making process. ${ }^{11-13}$

Insofar as the mentally handicapped person is competent to give informed consent, the decision of the individual should be respected. When a request for sterilisation is made by the parents or the guardian of the mentally handicapped person, the physician is confronted with a conflict of values and interests. First of all the physician has a duty to help the patient to reach full development, including possible parenthood, on the other hand he may not neglect his duty to make sure that the patient has the ability to raise and care for a future child.

If there are good and sound reasons for believing that the likelihood of a significant handicap of the future child is very great and/or the quality of the parental care would be minimal, a conflict arises between these negative factors and the legally protected right to have children.

This in turn means that the hereditary nature of the handicap and the parenting ability must be properly documented in order to arrive at an ethically acceptable decision.

We consider heredity and parenting ability to be major criteria because they relate to the optimisation of procreation and the propagation of life. The presence of one or both major criteria gives rise to a socalled "situation of necessity".

Let us now examine these major criteria.

\subsection{HEREDITY}

Mental retardation can have various aetiologies, hereditary or acquired: prenatal (single gene defects, chromosomal disorders, complex malformation syndromes), perinatal (complications of prematurity, hypoxic-ischemic insults, infection), and postnatal (infections, toxins such as lead, metabolic disorders, trauma, severe deprivation and other factors). In about $60 \%$ to $75 \%$ of children with severe mental retardation and in about $38 \%$ to $55 \%$ of children with mild mental retardation we can establish an aetiology for the mental retardation. In the other cases it is impos

The physician must therefore determine, as fart: as is possible, what the cause of the mental retar dation is and what is the chance that progeng could inherit the same disease. ${ }^{13}$ Individualisin every case is very important. It is also important $t \bar{\emptyset}$ obtain a genetic opinion when prenatal diagnosiô is involved and to discuss the results with the pare ties concerned. There is no reason to confuse thi $\vec{\rho}$ with eugenics, as sometimes occurs.

2.2. PARENTING COMPETENCE
The degree to which somebody is a competent parent can be seen as being on a continuum rango ing from $100 \%$ competent to $100 \%$ incompetentu Every individual, including the non-handicapped can be located on this continuum. Somewhere along this horizontal line there is a transition from competent to incompetent.

Assessing parenting competence is a difficul task, particularly when the assessor is required t $\vec{b}$ make this assessment when the person concerne@ is still adolescent. An opinion based on a thorougb psychological and social study is desirable. Here charting the individual's ability to manage on his or her own (social viability), using existing scale may be of some assistance. ${ }^{13}$

As the child grows up the caring aspects parenting give way to more complicated tasks.

The consequence may be that the children leave their parents' home, which can be highly disturb? ing to the mentally handicapped parent. In this connection Macklin and others have formulate six characteristics for assessing parental compe tence: lack of verbal skills; obtrusive deformation. of reality; persistent malice towards children? inconsistent value system; inability to transmif essential survival information or a model for life, and failure to establish and maintain interpersonat relationships. ${ }^{19}$

\section{Minor criteria}

Apart from the major criteria, there are six minot criteria which should be considered during the decision making process. The minor criteria are of an entirely different ethical order from the majog criteria. These criteria can really only be consid= ered once the major criteria have created a "situa tion of necessity". Their purpose is to help with the assessment of every individual situation.

\subsection{RISK OF CONCEPTION}

The first minor criterion is the risk of conception Many authors" 111517182122 refer to "risk \& conception" as an important element in the decio sion making process. 
Here various aspects are involved, including fertility, the presence of members of the opposite sex, sexual interest and sexual knowledge.

The first element is the fertility of the mentally handicapped individual. When there is no fertility, obviously, sterilisation is not needed. Another element is knowing whether the mentally handicapped person lives or will live in a mixed-sex environment. The expectations of the parents of the mentally handicapped regarding the future of their child in connection with marriage and parenthood or in connection with building an independent existence are likewise important elements. The appraisal of the future by professional supervisors can give an indication of whether the mentally handicapped person is likely to be supervised throughout his or her life.

The third element relates to sexual interest. This can be appraised by questions such as the following: does the mental handicapped person have sexual relations or is there reason to believe that he or she will have sexual relations in the near future; does the subject have a permanent relationship or does the subject have fleeting relationships; is there inappropriate sexual behaviour; is there sexual abuse; has pregnancy already occurred, and has the subject already undergone an abortion?

The fourth factor relates to any sex education which the mentally handicapped person may have received. An understanding of the anatomy and physiology of the reproductive organs and the relationship between coitus and pregnancy is essential if the subject is to be taught about contraceptives and their use either unaided or with assistance. ${ }^{20} \mathrm{~A}$ more broadly based approach could discuss sexual experience and personal relationships.

\subsection{IQ}

The intelligence quotient is a relative criterion and is most certainly not the most important. Far from all societies attach as much importance to intelligence criteria as we do. Intelligence quotient can change over the years. A recent IQ is needed as well as IQ values recorded over period of time. This will help in assessing possible change. ${ }^{13}$

\subsection{AGE}

If other ways of controlling fertility are available, sterilisation can be delayed until the adolescent reaches majority, or until his or her future is clearer. $^{20}$ The presence of a partner is, for example, a significant development as the couple may then decide whether to adopt contraceptive measures and what these should be. Pharmaceutical developments, such as the administration of subcutaneous gestagens, could offer attractive alternatives in the future, particularly for adolescent girls. Alternative methods to sterilisation must have been tried and found unsatisfactory ${ }^{211}$ before deciding for a sterilisation.

It is obvious that the situation is much more complicated for boys/men than for girls/women, because of the non-existence of acceptable reversible methods of contraception.

\subsection{PERSONALITY OF THE MENTALLY HANDICAPPED PARENT}

The evidence is that children benefit when their parents have stable personalities. Low self-esteem and feelings of inferiority make the task of raising children more difficult. It is also important to have a consistent system of values. The way in which the parents experience and assess the external world is a guiding factor. Behaviour may be socially acceptable or violent and destructive. ${ }^{19}$

\subsection{MEDICAL ASPECTS AND PROGNOSIS}

Medical assessment should determine if there are other problems, such as epilepsy, depression, psychiatric symptoms or handicaps that interfere with sensory or motor function or both so that self-care can be compromised.$^{13}$ It is also worth finding out if medicines must be regularly taken which interact with contraceptive drugs ${ }^{21}$ or which would harm the fetus in the event of pregnancy.

A full prognosis is also important, particularly for the assessment of adolescents when there is a likelihood that their condition may improve.

\subsection{SUPPORT AND GUIDANCE}

It is also wise to find out if there will be enough support and guidance for the relationship of the mental handicapped person and for any children. Parents and/or family and/or those in the the immediate environment must be asked if they are prepared to provide suitable support and guidance both in emotional and material terms as well as purely financially. ${ }^{16}$

Often the mentally handicapped person is cared for outside an institution and usually by parents. If there is a risk of conception, particularly if he or she is promiscuous, the parents are faced with what is often an ethically demanding issue of what to do if the result is an unwanted pregnancy. Their view on this matter should be at least as important as the rights of the handicapped.

\section{Conclusions}

In conclusion we wish to propose the following seven guidelines:

1. Before proceeding to the assessment of a request for sterilisation with consent given in 
the patient's stead, it must first be determined whether the mentally handicapped person is capable of deciding for him or herself. Should this be the case, the patient will be allowed to decide and the standards of the informed consent procedure will be applied.

2. The evaluation on which the decision to sterilise will be based will always be made on an individual basis in the context of the physician(team)/patient relationship on the basis of one or both major criteria: is there a hereditary factor and/or is there a lack of parenting capability

3. In view of the medical, psychological, social, educational, ethical and legal aspects of the decision a multidisciplinary approach is essential.

4. The mentally handicapped person must be involved in the decision making process as far as this is possible.

5. The best possible use should be made of opportunities for sexual education.

6. The decision making process regarding sterilisation must never be allowed to become a matter of urgency.

7. Counselling the parents can contribute to ensuring that the contraception problem is satisfactory resolved. A more broadly based approach could discuss sexual experience and personal relationships.

We grant the authority to take the decision to go ahead with sterilisation to the parent or the legal representative of the mentally handicapped person after a process of multidisciplinary consultation between the parent or legal representative and the patient's physician and his or her team. The mentally handicapped person will as far as possible be involved in this process. The underlying philosophy is a respect for private decision making in the family. There are other possibilities, but we do not discuss them here because this is not the purpose of our paper.

Partners in the multidisciplinary consultation process might include a (neuro)psychiatrist or psychologist, a special educationalist, the general practitioner, a social worker, and a specialist in a discipline such as paediatrics, genetics, internal medicine, gynaecology, urology etc, depending on the case at hand. ${ }^{11} 13$

The file on which the decision is based will contain a medical report, a psychological report and a social assessment. ${ }^{13} 1722$

Ultimately it comes down to deciding whether the benefits of sterilisation outweigh the drawbacks and whether the means are appropriate to the end, where efficient contraception is the en $\frac{\pi}{\tilde{\Phi}}$.
and irreversible sterilisation is the means.

Finally we wish to make it perfectly clear what the difference is between these medical and ethicaf proposals and any arrangements imposed by lave Lawmakers cannot take account of the specifit characteristics of the individual case. We do no support a "sterilisation law".

The individual approach, so fundamental to the problems under consideration here, is lost the moment it becomes enshrined in legal rules. Non $\vec{e}$ the less legislation is needed in order to put an en⿳亠口冋 to the legal uncertainty surrounding this problem Societal control of the ethics of the medical action taken is essential. Any legislation should deter mine the procedure whereby the decision is taken who should represent the mentally handicapped person, who gives consent on his or her behale and finally it should offer a way of reviewing the decision in the event of dispute.

Foke P M Denekens, MD, PhD, is Professor in Generat Practice, and Head of the Department of Gener\& Practice, University of Antwerp, Belgium. Hermai Nys, $M L, P h D$, is Professor in Medical Law ang Co-director of the Centre of Biomedical Ethics and Law, University of Leuven, Belgium. Hugo Stuem $M D$, is a General Practitioner and Assistant in th Department of General Practice, University Antwerp, Belgium. Correspondence address: Prof Do f P M Denekens, University of Antwerp, Department of General Practice, Universiteitsplein 1, 261 t? Antwerpen(Wilrijk), Belgium.

\section{References}

1 Bourguignon $\mathrm{HJ}$. Mental retardation: the reality behind the label. Cambridge Quarterly of Healthcare Ethics 1994;3:179-98

2 Applebaum GM, La Puma J. Sterilization and a mentall handicapped minor: providing consent for one who cannot. Cambridge Quarterly of Healthcare Ethics 1994;3:209-15.

3 Reilly PR. The surgical solution - a history of involuntary steriliz ation in the United States. Baltimore, Maryland: Johns Hopkinf University Press, 1991.

4 Spann W. Rechtsgrundlagen der operativen Sterilization bei Mann und bei der Frau in der Bundesrepublik Deutschlan Geburtzhilfe Frauenheilkunde 1975;35: 501-3.

5 Garber HL. The Milwaukee project, preventing mental retardatid in children at risk. Washington DC: American Association oN Mental Retardation, 1988.

6 Nirje B. The normalization principle and its human manage् ment implications. In: Kugel RB, Wofensburger W, eds. Changing patterns in residential services for the mentally retarded. Wasie ington DC: President's Committee on Mental Retardation 1969.

7 De Lion Siantz ML. Human values in determining the fate of persons with mental retardation. Nursing Clinics of North America 1979;14:57-67.

8 United Nations Organisation. Declaration on the rights mentally retarded persons. UN General Assembly 2027th Plenarf Meeting, 1971 Dec 20. New York: UNO, 1971

9 Chamberlain A, Rauh J, Passer A, McGrath M, Burkit R Issues in fertility control for mentally retarded femafe adolescents: I. Sexual activity, sexual abuse and contraception Pediatrics 1984;73: 445-50.

10 Denekens JPM. Sterilisatie en mentaal gehandicapten: wie beslis? (Sterilization of the mentally handicapped: who can givo. consent?) Antwerp,Belgium, academic dissertation (in Dutch 1992. 
11 Rauh JL, Dine MS, Biro FM, Rauh TD. Sterilization for the mentally retarded adolescent. Balancing the equities/the Cincinnati experience. Fournal of Adolescent Health Care 1989;10:467-72.

12 Eser A. Contraception and abortion of mentally handicapped female adolescents under German law. Medicine and Law 1985; 4:499-513.

13 Perrin JC, Sands CR, Tinker DE, Dominguez BC, Dingle JT, Thomas MJ. A considered approach to sterilization of mentally retarded youth. American fournal of Diseases of Children 1976;130:288-290.

14 Palmer FB, Capute AJ. Mental retardation. Pediatrics in Review 1994;15:473-9.

15 Karp LE. Sterilization of the retarded. American fournal of Medical Genetics 1981; 9:1-3.

16 Nash ES, Navias $M$. The therapeutic sterilization of the mentally handicapped. Experience with the Abortion and Sterilization Act of 1975. South Africa Medical fournal 1992;82:437-9.
17 McManus R. Sterilization and the mentally handicapped person. North Carolina Medical fournal 1983;44:92-3.

18 McLachlan R, Peppin P. Sexuality and contraception for developmentally handicapped persons. Canadian Family Physician 1986;32:1631-7.

19 Macklin R, Gaylin W, eds. Mental retardation and sterilization. A problem of competency and paternalism. New York and London: The Hastings Center Series in Ethics, Plenum Press, 1981.

20 Vining E, Freeman J. Sterilization and the retarded female: is advocacy depriving individuals of their rights? Pediatrics 1978; 62:850-3.

21 Hein K, Coupez SM, Cohen MI. Special considerations in pregnancy prevention for the mentally subnormal adolescent female. fournal of Adolescent Health Care 1980;1:46-9.

22 Elkins TE, Gafford LS, Wilks CS, Muram D, Golden G. A model clinic approach to the reproductive health concerns of the mentally handicapped. Obstetrics and Gynecology 1986;68: $185-8$

\section{News and notes}

\section{European Commission: call for research proposals}

The European Commission is publishing calls for proposals for research in the area of biomedical ethics and bioethics in 1999, 2000 and 2001 under the Fifth Framework Programme for Research and the Specific Programme for "Quality of Life and Management of Living Resources".

These calls are open to teams wishing to propose either research projects or concerted actions, research networks or conferences.

The first call's closing date is June 1999. A second call should be published with a closing date in October 1999.

This call will be covering areas such as: Ethical aspects of scientific and technological developments; Ethical framework for the life sciences; Public policies, law and bioethics, and Bioethics infrastructures and methodologies.

For more details or an information pack please contact Mr Maurizio Salvi at: fax: 32-2.299.58.88 or by email: maurizio.salvi@dg12.cec.be 